\title{
Case-control study of tobacco smoke exposure and breast cancer risk in Delaware
}

\author{
Dana E Rollison*1, Ross C Brownson ${ }^{2}$, H Leroy Hathcock ${ }^{3}$ and \\ Craig J Newschaffer ${ }^{4,5}$
}

\begin{abstract}
Address: ${ }^{1}$ Division of Cancer Prevention \& Control, H Lee Moffitt Cancer Center \& Research Institute; Tampa, FL, USA, ${ }^{2}$ Department of Community Health and Prevention Research Center, Saint Louis University School of Public Health, St Louis MO, USA, ${ }^{3}$ Delaware Division of Public Health, Dover, DE, USA, ${ }^{2}$ Department of Epidemiology and Biostatistics, Drexel University School of Public Health, Philadelphia, PA, USA and ${ }^{5}$ Department of Epidemiology, Johns Hopkins Bloomberg School of Public Health, Baltimore, MD, USA

Email: Dana E Rollison* - dana.rollison@moffitt.org; Ross C Brownson - brownson@slu.edu; H Leroy Hathcock - Leroy.Hathcock@state.de.us; Craig J Newschaffer - cnewscha@drexel.edu

* Corresponding author
\end{abstract}

Published: 2 June 2008

BMC Cancer 2008, 8:157 doi:10.1 |86/147|-2407-8-157
Received: 5 December 2007

Accepted: 2 June 2008

This article is available from: http://www.biomedcentral.com//47/-2407/8//57

(c) 2008 Rollison et al; licensee BioMed Central Ltd.

This is an Open Access article distributed under the terms of the Creative Commons Attribution License (http://creativecommons.org/licenses/by/2.0), which permits unrestricted use, distribution, and reproduction in any medium, provided the original work is properly cited.

\begin{abstract}
Background: Tobacco smoke exposure may be associated with increased breast cancer risk, although the evidence supporting the association is inconclusive. We conducted a case-control study in Delaware, incorporating detailed exposure assessment for active and secondhand smoke at home and in the workplace.
\end{abstract}

Methods: Primary invasive breast cancer cases diagnosed among female Delaware residents, ages 40-79, in 2000-2002 were identified through the Delaware cancer registry $(n=287)$. Delaware drivers license and Health Care Finance Administration records were used to select age frequencymatched controls for women $<65$ and $\geq 65$, respectively. Detailed information on tobacco smoke exposure was obtained through telephone interviews.

Results: A statistically significant increased risk of breast cancer was observed for ever having smoked cigarettes (odds ratio $=1.43,95 \%$ confidence interval $=1.03-1.99$ ). However, there was no evidence of a dose-response relationship between breast cancer risk and total years smoked, cigarettes per day, or pack-years. Neither residential nor workplace secondhand smoke exposure was associated with breast cancer. Recalculations of active smoking risks using a purely unexposed reference group of women who were not exposed to active or secondhand smoking did not indicate increased risks of breast cancer.

Conclusion: These findings do not support an association between smoking and breast cancer.

\section{Background}

More than 180,000 cases of breast cancer are expected to be diagnosed in the U.S. in 2008 [1]. While several reproductive and genetic risk factors for breast cancer have been well established in the epidemiologic literature, these fac- tors account for less than half of all breast cancer and are not modifiable [2]. Exposure to tobacco smoke is a potentially modifiable factor that may be associated with increased breast cancer risk, although evidence supporting the association is inconclusive. 
While some epidemiologic studies have observed associations between cigarette smoking and breast cancer, more studies have not $[3,4]$. Most studies of secondhand smoke exposure suggested no association with breast cancer risk [5-17], although a few have observed increased breast cancer risk among women exposed to secondhand tobacco smoke [18-21], particularly among premenopausal women [22] and women with exposure prior to first fullterm birth $[23,24]$. Notably, studies that measured detailed exposures to both active and secondhand tobacco smoke indicate that risk associated with active smoking may have been masked in earlier studies because women exposed to secondhand tobacco smoke were included in the reference groups [18-20,24-27]. A recent meta-analysis concluded that studies with more thorough assessment of exposure to tobacco smoke tended to support an association between breast cancer and both active and secondhand tobacco smoke, whereas studies with cruder exposure assessment were less likely to observe associations [28]. Here we report on a case-control study in Delaware, incorporating detailed exposures to active and secondhand smoke assessed both at home and in the workplace during critical periods in a woman's reproductive life.

\section{Methods \\ Study population}

Breast cancer cases were identified through the Delaware Cancer Registry, a statewide, population-based cancer registry maintained by the Delaware Division of Public Health. Cases were defined as female residents of Delaware, ages 40-79, diagnosed with microscopically-confirmed incident primary invasive breast cancer (International Classification of Diseases, $10^{\text {th }}$ revision (ICD-0) code 174) in 2000-2002. Cases were excluded from the study if they had a prior history of invasive breast cancer, lived in an institutional setting, or did not have a telephone. Physician approval was required prior to contacting cases. Potential participants were then mailed a letter and contacted by telephone 1-2 weeks later. Of the 1,076 potential cases identified through the Delaware Cancer Registry, physician permission was obtained to contact 617, of whom 217 could not be located or were not eligible for the study. Of the remaining 400 eligible cases, $28 \%$ refused to participate in the study, resulting in a final sample size of 287 cases. As compared to the cases who participated in the study, cases who were not contacted or refused to participate were somewhat less likely to be White, while no differences were observed between the groups by county or stage at diagnosis.

Controls were selected using two public databases: Delaware motor vehicle drivers license records for women $<65$ years and records maintained by the Health Care Finance Administration (HCFA), currently known as the Center for Medicare and Medicaid Services, for women 65+ years. Controls were frequency-matched to cases on age within 10-year groups. Telephone numbers were obtained using reverse telephone directories, and letters were mailed to women with phone number matches, informing women of their selection into the study and the phone call that they should anticipate. Potential controls were then called 1-2 weeks after letters were mailed, and of those eligible controls contacted, $46 \%$ participated.

Power calculations performed during the design phase of the study indicated that 300 breast cancer cases and 300 controls were needed in order to achieve $80 \%$ power to detect an odds ratio between active smoking and breast cancer of 1.6 at a significance level of $\mathrm{p}<0.05$, assuming the prevalence of exposure in controls was $47 \%$, the proportion of women of similar ages as the proposed controls who reported ever smoking in the Delaware Behavioral Risk Factor Surveillance Survey [29].

\section{Data collection}

In accordance with the study protocol, which was approved by the human subjects review boards at the Johns Hopkins Bloomberg School of Public Health, the Delaware Department of Health and Social Services, and the University of Delaware, informed consent was completed by phone. Trained interviewers administered a detailed questionnaire with smoking questions modeled after the Missouri Women's Health Study [30,31]. Each woman who had ever smoked (i.e. smoked at least 100 cigarettes in her lifetime) answered questions about the age she first smoked cigarettes, how many cigarettes she smoked per day, whether she smoked cigarettes that were filter versus non-filter, menthol versus non-menthol, and regular versus low-tar, if she usually inhaled smoke into the chest, and if in addition to cigarettes, she used any other type of tobacco product on a regular basis, including pipes, cigars, cigarillos, snuff, and chewing tobacco. If any of these characteristics of her smoking habits changed since she started smoking, then the age at the time of the change was recorded, and the same characteristics were assessed for the next smoking period.

Secondhand smoking in childhood ( $<18$ years) and adulthood was based on enumeration of smokers living in the participant's household. Then, for each smoker, the number of packs, cigars or pipefulls smoked per day were recorded, in addition to the hours/day the participant was exposed. As with active smoking, new data were collected any time any aspect of exposure changed. Occupational exposure to secondhand smoke involved enumeration of jobs with exposure and, for each job, reporting of length of employment and average daily hours of exposure. Subjects also provided a subjective rating of exposure intensity (light, moderate, heavy) for each job. Other questions 
on demographics, reproductive history, family history, exogenous hormone use, alcohol consumption, physical activity, sleeping habits, meat cooking and consumption, and other dietary factors were also included.

\section{Statistical methods}

Categorical variables were compared between cases and controls using the chi-square test or the Mantel-Haenzsel chi-square test for trend. Total years smoked were calculated by summing the lengths of each reported period of smoking. Average cigarettes per day were calculated by weighting the number of cigarettes smoked per day in each period by the number of years in that period, divided by the total number of years. Total pack-years were calculated as the product of total years and average cigarettes per day.

Secondhand smoking analyses were restricted to women who smoked less than 100 cigarettes in their lifetime. Total years of secondhand smoke exposure were calculated by summing years across all periods for which women reported residential secondhand smoke exposure. To facilitate comparison with findings from a previous study of detailed secondhand smoke exposure measures [18], a smoker-year was defined for each period of residential secondhand smoke exposure as the product of the number of years in the period and the number of smokers who smoked in the household during that period. Total smoker-years were calculated as the sum of smoker-years across periods. Pack-years were defined as the product of cigarettes smoked per day for a given smoker in a given period and the number of years in that period. Pack-years were summed across smokers for each period and then across periods to generate a total pack-year measure. Weighted pack-years were defined as the product of cigarettes smoked per day for each smoker in a given period, the number of hours the woman was exposed to that smoker's smoke each day in that period, and the times the number of years in a period, divided by 18 waking hours in a day. This measure was summed across smokers in each period and across periods to obtain a total weighted pack-years measure. Both years and smoker-years were calculated for all types of tobacco products combined. Average cigarettes per day, pack-years and weighted packyears were calculated for cigarette exposure only. All secondhand smoke exposure measures were calculated separately for childhood (exposure prior to age 18) and adulthood and summed to obtain a measure of lifetime secondhand smoking.

Associations between tobacco smoke exposure and breast cancer were estimated by using unconditional logistic regression. For initial active smoking analyses, never active smokers (women who never smoked 100 cigarettes) were the reference group. For secondhand smoke exposure, never active smokers unexposed to secondhand smoke comprised the reference group. Additional active smoking analyses were conducted, using three more restrictive reference groups based on secondhand exposure data; those with: 1) zero years of lifetime residential secondhand smoke exposure and zero years of occupational secondhand smoke exposure; 2 ) $\leq 10$ years of lifetime residential secondhand smoke exposure, $\leq 10$ years of moderate-level occupational secondhand smoke exposure, and $\leq 10$ years of heavy-level occupational secondhand smoke exposure; or 3) zero years of residential secondhand smoke exposure before age of 18 . Women missing data for any smoker in any period were coded to missing for the corresponding summary variable.

Initial regression models included age and menopausal status, given their strong associations with breast cancer. Additional potential confounders were tested individually. If the risk estimate associated with smoking changed by 10 percent in either direction, that variable was included in a full model. If the smoking variables were multilevel, then a factor was included in the final model if it affected 1 out of 2 or 2 out of $3+$ levels. Potential confounders were assessed separately for active and passive tobacco smoke exposure. Separate models were also constructed for pre- and postmenopausal women.

\section{Results}

Selected characteristics of cases and controls are presented in Table 1. Controls were disproportionately premenopausal and college-educated, but similar to cases on other characteristics. Ever-active smoking was associated with a statistically significant increased risk of breast cancer (OR $=1.43,95 \%$ confidence interval $(\mathrm{CI})=1.03-1.99$ ) (Table 2 ). However, there was no evidence of a dose-response trend in breast cancer risk for total years smoked, average number of cigarettes per day or total pack-years. Ever active smoking prior to the age of 18 was associated with increased risk, but the magnitude of the association was not greater than that for ever smoking overall, and there was no dose response for years smoked prior to age 18 . Active smoking before first live birth was not associated with increased risk of breast cancer (Table 2). The risk of breast cancer associated with ever having smoked cigarettes was similar for premenopausal women (30 cases, 65 controls; $\mathrm{OR}=1.53,95 \% \mathrm{CI}=0.60-3.95)$ and postmenopausal women (256 cases, 246 controls; OR $=1.36,95 \%$ $\mathrm{CI}=0.95-1.94)$. Analyses limited to different types of cigarettes or inhalation levels did not reveal additional associations (data not shown).

Among never active smokers, secondhand smoke exposure in the home during childhood was not associated with breast cancer risk, whether exposure was measured in total years, smoker-years, pack-years or weighted pack- 
Table I: Selected characteristics of breast cancer cases and controls, Delaware, 2000-2002

\begin{tabular}{|c|c|c|c|c|c|}
\hline \multirow[b]{2}{*}{ Characteristic } & \multicolumn{2}{|c|}{ cases $(n=287)$} & \multicolumn{2}{|c|}{ controls $(n=31 I)$} & \multirow[b]{2}{*}{$\mathrm{p}$-value ${ }^{\mathrm{a}}$} \\
\hline & $\mathrm{n}$ & $\%$ & $\mathrm{n}$ & $\%$ & \\
\hline \multicolumn{6}{|l|}{ Age at interview (years) } \\
\hline $40-49$ & 53 & 18.5 & 63 & 20.3 & \\
\hline $50-59$ & 74 & 25.8 & 94 & 30.2 & \\
\hline $60-69$ & 87 & 30.3 & 77 & 24.8 & \\
\hline $70-80$ & 73 & 25.4 & 77 & 24.7 & 0.32 \\
\hline \multicolumn{6}{|l|}{ Race } \\
\hline White & 264 & 92.0 & 294 & 94.5 & \\
\hline Black/Other & 23 & 8.1 & 17 & 5.5 & 0.21 \\
\hline \multicolumn{6}{|l|}{ Education ${ }^{\mathrm{b}}$} \\
\hline$<12$ grades & 30 & 10.5 & 14 & 4.5 & \\
\hline 12 grades & 114 & 39.9 & 108 & 37.8 & \\
\hline some college & 108 & 37.8 & 148 & 47.6 & \\
\hline post-college & 34 & 11.9 & 41 & 13.2 & $<0.01$ \\
\hline \multicolumn{6}{|l|}{ Menopausal status } \\
\hline premenopausal & 30 & 10.5 & 65 & 20.9 & \\
\hline postmenopausal & 257 & 89.6 & 246 & 79.1 & $<0.01$ \\
\hline \multicolumn{6}{|l|}{ Body mass index $(\mathrm{kg} / \mathrm{m} 2)^{\mathrm{b}}$} \\
\hline $15-24$ & 107 & 37.3 & 122 & 39.6 & \\
\hline $25-29$ & 102 & 35.5 & 114 & 37.0 & \\
\hline $30-88$ & 78 & 27.2 & 72 & 23.4 & 0.56 \\
\hline \multicolumn{6}{|l|}{ Age at menarche (years) ${ }^{\mathrm{b}}$} \\
\hline $8-12$ & 140 & 49.3 & 142 & 45.8 & \\
\hline $13-18$ & 144 & 50.7 & 168 & 54.2 & 0.39 \\
\hline \multicolumn{6}{|l|}{ Number of Live Births ${ }^{b}$} \\
\hline nulliparous ${ }^{c}$ & 44 & 15.3 & 35 & 11.3 & \\
\hline $1-2$ & 128 & 44.6 & 145 & 46.8 & \\
\hline $3-4$ & 97 & 33.8 & 112 & 36.1 & \\
\hline $5-11$ & 18 & 6.3 & 18 & 5.8 & 0.52 \\
\hline \multicolumn{6}{|l|}{ Age at Ist live birth (years) ${ }^{b}$} \\
\hline$<30$ & 219 & 90.1 & 242 & 88.0 & \\
\hline $30+$ & 24 & 9.9 & 33 & 12.0 & 0.44 \\
\hline \multicolumn{6}{|l|}{ Oral contraceptive use } \\
\hline Never & 120 & 41.8 & 110 & 35.4 & \\
\hline Ever & 167 & 58.2 & 201 & 64.6 & 0.11 \\
\hline \multicolumn{6}{|l|}{ Other hormone use $\mathrm{e}^{\mathrm{b}}$} \\
\hline Never & 153 & 53.3 & 161 & 51.9 & \\
\hline Ever & 134 & 46.7 & 149 & 48.1 & 0.74 \\
\hline \multicolumn{6}{|l|}{ Family History of Breast Cancer ${ }^{b, c}$} \\
\hline No & 220 & 77.7 & 257 & 82.9 & \\
\hline Yes & 63 & 22.3 & 53 & 17.1 & 0.11 \\
\hline \multicolumn{6}{|l|}{ Alcohol consumption } \\
\hline$<12$ drinks in lifetime & 37 & 12.9 & 49 & 15.8 & \\
\hline$\geq 12$ drinks in lifetime, but never had $\geq 1$ drink per mo. for $\geq 6$ mos & 87 & 30.3 & 85 & 27.3 & \\
\hline drank $\geq$ I drink per mo. for $\geq 6$ mos & 163 & 56.8 & 177 & 56.9 & 0.52 \\
\hline
\end{tabular}

a $\mathrm{p}$-values based on chi-square test; $\mathrm{p}$-values based on Mantel-Haenszel chi-square test for trend for the following variables: age, education, BMI, and age at first live birth

b Numbers do not always sum to total number of cases and/or controls due to missing information

c Includes 9 cases and 10 controls who reported I+ pregnancies

d Family history of breast cancer defined as mother or sister ever diagnosed with breast cancer

years (see additional file 1). Weighting pack-years by the number of hours exposed to secondhand tobacco smoke each day did not result in any considerable differences in breast cancer risks (see additional file 1). Similarly, secondhand smoke exposure in the home during adulthood was not associated with breast cancer risk, regardless of the exposure metric used $(\mathrm{OR}=0.98,95 \% \mathrm{CI}=0.58-$ 1.64). Combining childhood and adulthood exposures, no increased risks were observed with 45 or more packyears of lifetime residential secondhand smoke. Second- 
Table 2: Active smoking and breast cancer among cases and controls, Delaware, 2000-2002

\begin{tabular}{|c|c|c|c|c|c|c|}
\hline \multirow[b]{2}{*}{ Active smoke exposure } & \multicolumn{2}{|c|}{ cases } & \multicolumn{2}{|c|}{ controls } & \multirow[t]{2}{*}{ odds ratio ${ }^{a}$} & \multirow[t]{2}{*}{$95 \%$ confidence intervala $^{a}$} \\
\hline & $\mathrm{n}$ & $\%$ & $\mathrm{n}$ & $\%$ & & \\
\hline \multicolumn{7}{|c|}{ Ever smoked 100 cigarettes } \\
\hline No & 124 & 43.2 & 161 & 51.8 & 1.00 & reference \\
\hline Yes & 163 & 56.8 & 150 & 48.2 & 1.43 & $1.03-1.99$ \\
\hline \multicolumn{7}{|c|}{ Total years smoked cigarettes ${ }^{\mathrm{b}}$} \\
\hline$<10$ & 23 & 8.0 & 26 & 8.4 & 1.36 & $0.72-2.55$ \\
\hline $10-19$ & 27 & 9.4 & 33 & 10.6 & 1.13 & $0.64-2.01$ \\
\hline $20-29$ & 34 & 11.9 & 26 & 8.4 & 1.80 & $1.02-3.20$ \\
\hline $30-39$ & 36 & 12.6 & 32 & 10.3 & 1.31 & $0.76-2.25$ \\
\hline $40-49$ & 27 & 9.4 & 21 & 6.8 & 1.50 & $0.79-2.82$ \\
\hline $50-62$ & 15 & 5.2 & 12 & 3.9 & 1.21 & $0.52-2.84$ \\
\hline \multicolumn{7}{|c|}{ Average number of cigarettes/dayb } \\
\hline$<10$ & 58 & 20.5 & 49 & 15.9 & 1.60 & $\mathrm{I} .0 \mathrm{I}-2.53$ \\
\hline $10-19$ & 67 & 23.7 & 58 & 18.8 & 1.53 & $0.99-2.35$ \\
\hline $20-29$ & 25 & 8.8 & 29 & 9.4 & 1.12 & $0.6 I-2.04$ \\
\hline $30-68$ & 9 & 3.2 & 12 & 3.9 & 0.84 & $0.34-2.08$ \\
\hline \multicolumn{7}{|l|}{ Total pack-years $\mathrm{b}$} \\
\hline$<5$ & 37 & 13.1 & 36 & 11.7 & 1.45 & $0.85-2.45$ \\
\hline $5-9$ & 19 & 6.7 & 18 & 5.8 & 1.65 & $0.8 I-3.35$ \\
\hline $10-19$ & 37 & 13.1 & 26 & 8.4 & 1.83 & $1.04-3.23$ \\
\hline $20-29$ & 28 & 9.9 & 29 & 9.4 & 1.24 & $0.69-2.24$ \\
\hline $30-39$ & 10 & 3.5 & 12 & 3.9 & 1.06 & $0.44-2.56$ \\
\hline $40-49$ & 16 & 5.7 & 9 & 2.9 & 1.92 & $0.8 I-4.55$ \\
\hline $50-102$ & 12 & 4.2 & 18 & 5.8 & 0.75 & $0.34-1.65$ \\
\hline \multicolumn{7}{|c|}{ Years smoked at or before age $18 \mathrm{c}$} \\
\hline$<5$ & 93 & 32.4 & 91 & 29.3 & 1.34 & $0.91-1.96$ \\
\hline $5-10$ & 16 & 5.6 & 15 & 4.8 & 1.33 & $0.62-2.85$ \\
\hline \multicolumn{7}{|c|}{ Years smoked, before first live birth ${ }^{d}$} \\
\hline Never smokers & 108 & 37.6 & 138 & 44.4 & 1.00 & reference \\
\hline$<5$ & 38 & 13.2 & 36 & 11.6 & 1.25 & $0.73-2.13$ \\
\hline $5-9$ & 59 & 20.6 & 55 & 17.7 & 1.37 & $0.87-2.16$ \\
\hline $10-14$ & 12 & 4.2 & 27 & 8.7 & 0.69 & $0.33-1.45$ \\
\hline $15-39$ & 11 & 3.8 & 9 & 2.9 & 1.99 & $0.76-5.18$ \\
\hline
\end{tabular}

a adjusted for age, education, and menopausal status

b Numbers do not always total due to missing data

c Excludes women who smoked only after age 18

d Excludes nulliparous women and those who smoked only after the birth of their first child

hand smoke exposure at work was not associated with increased breast cancer risk, even when considering 20-45 years of exposure duration and "heavy" self-rated intensity of exposure (Table 3 ).

In active smoke exposure re-analyses, only 13 cases and 14 controls comprised the most stringent reference group of ever active smokers with no secondhand smoke exposure at home or at work during their lifetimes (Table 4). Using this reference group, ever having smoked cigarettes was not statistically significantly associated with breast cancer $(\mathrm{OR}=1.21,95 \% \mathrm{CI}=0.55-3.32)$, after adjustment for age and menopausal status. There was no evidence of a doseresponse relationship between smoking and breast cancer risk using this reference group, nor were exposures before 18 or before first live birth associated with breast cancer (Table 4). As mentioned, to increase the sample size of the reference group, two less stringent definitions were considered, but no statistically significant associations were observed using either of these alternative reference groups (Table 4).

\section{Discussion}

Overall, our findings do not support exposure to active or secondhand tobacco smoke as a risk factor for breast cancer. A statistically significant increased risk of breast cancer was observed for ever having smoked at least 100 cigarettes in one's lifetime. However, the magnitude of this risk was modest $(\mathrm{OR}=1.43)$ and decreased rather than increased with use of more stringent reference groups excluding those exposed to secondhand smoke. Additionally, there was no evidence of a dose-response relationship between breast cancer risk and total years smoked, cigarettes per day, or pack-years. Residential exposure to 
Table 3: Secondhand smoke exposure at work and breast cancer among non-smoking cases and controls from Delaware

\begin{tabular}{|c|c|c|c|c|c|c|}
\hline \multirow[t]{2}{*}{ Secondhand smoke exposure at work ${ }^{a}$} & \multicolumn{2}{|c|}{ cases } & \multicolumn{2}{|c|}{ controls } & \multirow[t]{2}{*}{ odds ratiob } & \multirow[t]{2}{*}{$95 \%$ confidence Interval ${ }^{b}$} \\
\hline & $\mathrm{n}$ & $\%$ & $\mathrm{n}$ & $\%$ & & \\
\hline \multicolumn{7}{|l|}{ Never employed or } \\
\hline not exposed at work & 60 & 48.4 & 69 & 43.4 & 1.00 & Reference \\
\hline Any secondhand smoke exposure at work & 64 & 51.6 & 90 & 56.6 & 0.80 & $0.49-1.32$ \\
\hline \multicolumn{7}{|c|}{ Number of years employed at a job with secondhand smoke exposure } \\
\hline$<10$ & 27 & 21.8 & 48 & 30.1 & 0.66 & $0.35-1.23$ \\
\hline $10-19$ & 24 & 19.4 & 27 & 17.0 & 1.02 & $0.52-2.00$ \\
\hline $20-45$ & 13 & 10.5 & 15 & 9.4 & 0.86 & $0.35-2.07$ \\
\hline \multicolumn{7}{|c|}{ Number of years employed at a job with light secondhand smoke exposure } \\
\hline$<10$ & 17 & 13.7 & 27 & 17.0 & 0.96 & $0.46-1.97$ \\
\hline$\geq 10$ & 13 & 10.5 & 13 & 8.2 & 1.14 & $0.47-2.78$ \\
\hline \multicolumn{7}{|c|}{ Number of years employed at a job with moderate secondhand smoke exposure } \\
\hline$<10$ & 11 & 8.9 & 16 & 10.1 & 0.70 & $0.29-1.68$ \\
\hline$\geq 10$ & 17 & 13.7 & 22 & 13.8 & 1.01 & $0.49-2.09$ \\
\hline \multicolumn{7}{|c|}{ Number of years employed at a job with heavy secondhand smoke exposure } \\
\hline$<10$ & 5 & 4.0 & 8 & 5.0 & 1.02 & $0.31-3.37$ \\
\hline$\geq 10$ & 7 & 5.6 & 7 & 4.4 & 1.07 & $0.35-3.30$ \\
\hline
\end{tabular}

a 2 non-smoking controls were missing data on exposure to smoke at work

${ }^{b}$ Adjusted for age, menopausal status, body mass index $(<25,25-29,30+)$, age at menarche $(<12$ vs. $12+)$, age at first live birth (nulliparous, $<30$,

$30+$ ), oral contraceptive use (ever vs. never), other hormone use (ever vs. never), family history of breast cancer (yes vs. no), alcohol consumption (ever drank 12 drinks in lifetime vs. had 12 drinks in lifetime but never had I+ drink per month for 6+ months vs. ever had I+ drink per month for

$6+$ months); data for adjustment factors was missing for 4 cases and 3 controls

Table 4: Active smoking and breast cancer among cases and controls from Delaware, using women never exposed to active or secondhand smoking as the reference group

\begin{tabular}{|c|c|c|c|c|c|c|c|c|}
\hline \multirow[t]{2}{*}{ Active cigarette smoking exposure } & \multicolumn{4}{|c|}{ Unexposed definition \# |a } & \multicolumn{2}{|c|}{ Definition \# 2} & \multicolumn{2}{|c|}{ Definition \# 3} \\
\hline & cases & controls & $\mathrm{OR}^{\mathrm{b}}$ & $95 \% \mathrm{Cl}^{\mathrm{b}}$ & $\mathrm{OR}^{\mathrm{b}}$ & $95 \% \mathrm{Clb}^{\mathrm{b}}$ & $\mathrm{OR}^{\mathrm{b}}$ & $95 \% \mathrm{Clb}^{\mathrm{b}}$ \\
\hline \multicolumn{9}{|c|}{ Unexposed to active and secondhand smoke } \\
\hline Definition \# I & 13 & 14 & 1.00 & reference & & & & \\
\hline Definition \# 2 & 30 & 37 & & & 1.00 & reference & & \\
\hline Definition \# 3 & 41 & 46 & & & & & 1.00 & reference \\
\hline Ever active smoker & 163 & 150 & 1.21 & $0.55-2.66$ & 1.33 & $0.77-2.27$ & 1.23 & $0.76-1.98$ \\
\hline \multicolumn{9}{|l|}{ Years of smokingb } \\
\hline$<20$ & 50 & 59 & 0.98 & $0.42-2.31$ & 1.10 & $0.59-2.05$ & 1.03 & $0.58-1.82$ \\
\hline $20-39$ & 70 & 58 & 1.31 & $0.57-3.02$ & 1.45 & $0.80-2.63$ & 1.35 & $0.77-2.36$ \\
\hline$\geq 40$ & 42 & 33 & 1.35 & $0.55-3.32$ & 1.48 & $0.74-2.96$ & 1.31 & $0.69-2.47$ \\
\hline \multicolumn{9}{|l|}{ Cigarettes per dayc } \\
\hline$<10$ & 58 & 49 & 1.31 & $0.56-3.08$ & $\mathrm{I} .45$ & $0.78-2.7 \mid$ & 1.33 & $0.75-2.35$ \\
\hline $10-19$ & 67 & 58 & 1.30 & $0.56-3.00$ & 1.44 & $0.79-2.63$ & 1.33 & $0.76-2.32$ \\
\hline$\geq 20$ & 34 & 41 & 0.90 & $0.37-2.18$ & 0.99 & $0.51-1.94$ & 0.91 & $0.49-1.69$ \\
\hline \multicolumn{9}{|l|}{ Pack-yearsc } \\
\hline$<10$ & 56 & 54 & 1.20 & $0.5 \mathrm{I}-2.8 \mathrm{I}$ & 1.34 & $0.72-2.48$ & 1.25 & $0.70-2.21$ \\
\hline $10-29$ & 65 & 55 & 1.30 & $0.56-3.01$ & 1.43 & $0.78-2.63$ & 1.32 & $0.75-2.31$ \\
\hline$\geq 30$ & 38 & 39 & 1.03 & $0.43-2.49$ & 1.13 & $0.58-2.20$ & 1.02 & $0.55-1.89$ \\
\hline Any exposure before age 18 & 109 & 106 & 1.13 & $0.5 \mathrm{I}-2.52$ & 1.27 & $0.73-2.21$ & 1.18 & $0.71-1.95$ \\
\hline Any exposure before first live birth & 120 & 127 & 1.06 & $0.48-2.35$ & 1.18 & $0.68-2.04$ & 1.08 & $0.66-1.76$ \\
\hline
\end{tabular}

a Women unexposed to secondhand smoke were defined as follows: Definition \#I: Zero years lifetime residential and occupational exposure; Definition \#2: $\leq 10$ years lifetime residential exposure, $\leq 10$ years of moderate-level occupational exposure and $\leq 10$ years heavy-level occupational exposure; Definition \#3: Zero years of residential exposure before age 18

b OR, odds ratio; $\mathrm{Cl}$, confidence interval; adjusted for age and menopausal status

c Data missing on total years smoked for I case, and cigs/day and pack-years for 4 cases and 2 controls 
secondhand smoke was not associated with breast cancer risk, whether the exposure occurred in childhood or adulthood. No increased risk of breast cancer was associated with heavy exposure to secondhand smoke at work. No large differences in breast cancer risk associated with secondhand smoke were observed by menopausal status.

Our findings for secondhand smoke are consistent with the 2002 International Agency for Research on Cancer Monograph on Tobacco Smoking and Tobacco Smoke, which stated that existing evidence was inconsistent and did not support a causal association between passive smoking and breast cancer [32]. In contrast, the more recent report published by the California Environmental Protection Agency concluded that the weight of the evidence was consistent with a causal association between secondhand smoke exposure and breast cancer diagnosed in women younger than age 50 who are mostly premenopausal [33]. Premenopausal women accounted for only 11 percent of the breast cancer cases included in the present study, thus, power to assess differences in risk by menopausal status was limited.

Although a number of previous studies report no association between active smoking and breast cancer risk (reviewed in $[3,4]$ ), these tended to use less intensive exposure assessment and include all non-smokers in the reference group. Our study, which meets criteria for high quality exposure assessment as outlined in a recent metaanalysis [28], found no association when the reference group excluded women with secondhand smoke exposure in contrast to other past studies meeting these criteria [19,20,24-28]. Use of a more stringent reference group did not increase the smoking risk ratios in part because of the limited number of women who had no active or passive smoke exposure and the lack of an association between secondhand smoking and breast cancer in this sample. This association was not seen despite collection of extensive secondhand smoke exposure histories, including the number of smokers in the home, the amount smoked by each smoker, and the hours per day of exposure to others' smoke, both in childhood and adulthood, in addition to secondhand smoke exposures at the workplace. It is highly unlikely that any major sources of secondhand smoke were missed in this study.

Some have suggested that there may be a critical period for exposure to active and/or secondhand smoking at early ages, prior to the birth of a first baby when cellular differentiation within the breast is completed [23,24]. In our study, women who reported smoking prior to age 18 or prior to their first live birth were not more likely to have breast cancer than those who did not actively smoke during these periods, even after restriction of the reference group to women who were not exposed to secondhand smoke in childhood. Our findings are consistent with a recent meta-analysis of 12 studies $[6,11,14,19,23,24,34$ 38] that calculated a pooled risk estimate of 1.07 (95\% CI: $0.72,1.00)$, concluding that active smoking prior to first live birth is not associated with breast cancer [38]. Results from the California Teacher's Study recently suggested that only long duration tobacco smoke exposure prior to the first live birth increased breast cancer risk [39]. We did not observe differences in breast cancer risk associated with 30 or more pack-years of active smoking among those with five or more years of pre-partum tobacco smoke exposure $(\mathrm{OR}=1.78,95 \% \mathrm{CI}=0.66-4.85)$ versus those with less than five years of exposure $(\mathrm{OR}=0.94$, $95 \% \mathrm{CI}=0.50-1.77)$. However, among nulliparous women in this study, 28 of 44 cases and 12 of 35 controls reported ever smoking 100 cigarettes in their lifetime (OR $=3.34,95 \% \mathrm{CI}=1.31-8.48)$, and when the reference group was restricted to women with zero years of residential secondhand smoke exposure before the age of 18 , the risk of breast cancer associated with ever smoking 100 cigarettes became even stronger ( $\mathrm{OR}=8.11,95 \% \mathrm{CI}=1.22-$ 53.92 ), but was based on only 15 cases and 10 controls. Larger studies should attempt to replicate these small subgroup findings, since nulliparous women are unique in that their entire life of exposure is "prepartum" and may represent a susceptible subgroup to particular exposures related to increased breast cancer risk.

The statistically significant increased risk of breast cancer we observed for ever smoking juxtaposed with the lack of a dose-response relationship observed for any measure of frequency or duration suggests that the former association may be due to confounding. In a recent cross-sectional analysis from the California Teacher's Study [40], active smoking was associated with increased alcohol consumption, nulliparity, and among parous women, and later age at first birth. These factors were systematically assessed as potential confounders in the present study, and none affected the smoking odds ratios by 10 percent or greater. However, the observed overall association between ever smoking and breast cancer could be confounded by unknown factors. Recall bias may also explain the statistically significant increased risk of breast cancer observed with ever smoking, if the controls were less likely to remember past exposures than the cases. Alternatively, the association could simply be due to chance or could be due to differential nonparticipation among controls that were active smokers. While control non-participation rates were comparable to those from other breast cancer casecontrol studies $[41,42]$ they were of a magnitude where differential participation would likely influence odds ratio estimates. That said, one case-control study with similar control non-participation rate still observed increased risk among long-term smokers compared to non-smokers [42]. 
As mentioned earlier, there was also non-participation among cases. If smoking was related to a more aggressive form of breast cancer, a greater proportion of cases who smoked may have been excluded by physicians for medical reasons, resulting in a bias toward the null. However, the overall percentage of cases diagnosed at advanced stages was small, and stage distribution was similar across participants and non-participants. Alternatively, the null associations with breast cancer risk observed for quantitative measures of active smoking and secondhand smoke exposure may be due to negative confounding by unmeasured factors, although it is difficult to speculate what these confounders could be. Non-differential misclassification of tobacco smoke exposures could have also biased the results toward the null if both the cases and the controls had equal difficulty recalling their lifetime exposures to tobacco smoke.

\section{Conclusion}

In conclusion, exposure to tobacco smoke, either through active or secondhand smoking, was not associated with breast cancer risk in this Delaware population. Women should still be encouraged to avoid tobacco smoke exposure to prevent other adverse health effects associated with both active and secondhand smoking.

\section{Competing interests}

The authors declare that they have no competing interests.

\section{Authors' contributions}

DER participated in the coordination of the study, performed the statistical analyses and drafted the manuscript. RCB and HLH participated in the design of the study and helped to draft the manuscript. CJN conceived of the study, participated in its design and coordination, and helped to draft the manuscript. All authors read and approved the final manuscript.

\section{Additional material}

\section{Additional file 1}

Secondhand smoke exposure at home among non-smoking breast cancer cases and controls from Delaware. Table.

Click here for file

[http://www.biomedcentral.com/content/supplementary/14712407-8-157-S1.doc]

\section{Acknowledgements}

This study was supported in part by the American Cancer Society. DER was supported by grant 2 T32 CA093-14-19 from the National Cancer Institute. We thank the Delaware Cancer Registry for providing information on breast cancer cases, especially the perseverance of Colleen Ferber. We also thank Dr. Edward Ratledge, Roberta Gibson, Jo-Ell Malloy and all of the dedicated interviewers at the University of Delaware Center for Applied
Demography and Survey Research for their contributions to control selection and data collection. The authors acknowledge the cooperation of Delaware physicians who allowed us to contact their patients.

\section{References}

I. Cancer Facts and Figures 2008. Atlanta, GA, American Cancer Society; 2008.

2. Rockhill B, Weinberg CR, Newman B: Population attributable fraction estimation for established breast cancer risk factors: considering the issues of high prevalence and unmodifiability. Am J Epidemiol 1998, 147:826-833.

3. Palmer JR, Rosenberg L: Cigarette smoking and the risk of breast cancer. Epidemiol Rev 1993, I5:|45-I56.

4. Terry PD, Rohan TE: Cigarette smoking and the risk of breast cancer in women: a review of the literature. Cancer Epidemiol Biomarkers Prev 2002, I I:953-97I.

5. Delfino RJ, Smith C, West JG, Lin HJ, White E, Liao SY, Gim JS, Ma $\mathrm{HL}$, Butler J, Anton-Culver $\mathrm{H}$ : Breast cancer, passive and active cigarette smoking and $\mathbf{N}$-acetyltransferase 2 genotype. Pharmacogenetics 2000, I0:46I-469.

6. Egan KM, Stampfer MJ, Hunter D, Hankinson S, Rosner BA, Holmes $M$, Willett WC, Colditz GA: Active and passive smoking in breast cancer: prospective results from the Nurses' Health Study. Epidemiology 2002, I 3: | 38- | 45.

7. Gammon MD, Eng SM, Teitelbaum SL, Britton JA, Kabat GC, Hatch $M$, Paykin AB, Neugut AI, Santella RM: Environmental tobacco smoke and breast cancer incidence. Environ Res 2004, 96: $176-185$.

8. Hanaoka T, Yamamoto S, Sobue T, Sasaki S, Tsugane S: Active and passive smoking and breast cancer risk in middle-aged Japanese women. Int J Cancer 2005, I | 4:3 I 7-322.

9. Hirayama T: Lung cancer and other diseases related to passive smoking: a large-scale cohort study. In Control of tobacco related cancers and other diseases, international symposium 1990 Edited by: PC G, JE HIII and PR M. Bombay, Oxford University Press; I992: I29-I 37.

10. Jee $\mathrm{SH}$, Ohrr H, Kim IS: Effects of husbands' smoking on the incidence of lung cancer in Korean women. Int J Epidemiol I999, 28:824-828.

II. Lash TL, Aschengrau A: A null association between active or passive cigarette smoking and breast cancer risk. Breast Cancer Res Treat 2002, 75:181-184.

12. Millikan RC, Pittman GS, Newman B, Tse CK, Selmin O, Rockhill B, Savitz D, Moorman PG, Bell DA: Cigarette smoking, $\mathbf{N}$-acetyltransferases I and 2, and breast cancer risk. Cancer Epidemiol Biomarkers Prev 1998, 7:371-378.

13. Nishino $Y$, Tsubono $Y$, Tsuji I, Komatsu S, Kanemura S, Nakatsuka $H$, Fukao A, Satoh H, Hisamichi S: Passive smoking at home and cancer risk: a population-based prospective study in Japanese nonsmoking women. Cancer Causes Control 2001, I 2:797-802.

14. Reynolds P, Hurley S, Goldberg DE, Anton-Culver H, Bernstein L, Deapen D, Horn-Ross PL, Peel D, Pinder R, Ross RK, West D, Wright WE, Ziogas A: Active smoking, household passive smoking, and breast cancer: evidence from the California Teachers Study. J Natl Cancer Inst 2004, 96:29-37.

15. Sandler DP, Everson RB, Wilcox AJ: Passive smoking in adulthood and cancer risk. Am J Epidemiol 1985, I 2 I:37-48.

16. Shrubsole MJ, Gao YT, Dai Q, Shu XO, Ruan ZX, Jin F, Zheng W: Passive smoking and breast cancer risk among non-smoking Chinese women. Int J Cancer 2004, I I 0:605-609.

17. Wartenberg D, Calle EE, Thun MJ, Heath CW Jr., Lally C, Woodruff $\mathrm{T}$ : Passive smoking exposure and female breast cancer mortality. J Natl Cancer Inst 2000, 92: I666-1673.

18. Johnson KC, Hu J, Mao Y: Passive and active smoking and breast cancer risk in Canada, 1994-97. The Canadian Cancer Registries Epidemiology Research Group. Cancer Causes Control 2000, I |:2 | |-22|.

19. Kropp S, Chang-Claude J: Active and passive smoking and risk of breast cancer by age $\mathbf{5 0}$ years among German women. Am J Epidemiol 2002, I 56:616-626.

20. Morabia A, Bernstein M, Heritier S, Khatchatrian N: Relation of breast cancer with passive and active exposure to tobacco smoke. Am J Epidemiol 1996, 143:918-928.

21. Smith SJ, Deacon JM, Chilvers CE: Alcohol, smoking, passive smoking and caffeine in relation to breast cancer risk in 
young women. UK National Case-Control Study Group. Br J Cancer 1994, 70:1 I2-119.

22. Lee PN, Hamling J: Environmental tobacco smoke exposure and risk of breast cancer in nonsmoking women: a review with meta-analyses. Inhal Toxicol 2006, 18:1053-1070.

23. Innes KE, Byers TE: Smoking during pregnancy and breast cancer risk in very young women (United States). Cancer Causes Control 200I, I 2:179-185.

24. Lash TL, Aschengrau A: Active and passive cigarette smoking and the occurrence of breast cancer. Am J Epidemiol 1999, I 49:5-12.

25. Wells AJ: Breast cancer, cigarette smoking, and passive smoking. Am J Epidemiol 1991, I33:208-210.

26. Wells AJ: Re: "Breast cancer, cigarette smoking, and passive smoking". Am J Epidemiol 1998, |47:99|-992.

27. Wells Aj: Re: Passive smoking exposure and female breast cancer mortality. J Natl Cancer Inst 200I, 93:717-7I9.

28. Johnson KC: Accumulating evidence on passive and active smoking and breast cancer risk. Int J Cancer 2006, 1 1 7:6 | 9-628.

29. Delaware Health and Social Services DPH: Behavioral Risk Factor Surveillance System (BRFSS). 1995.

30. Brownson RC, Alavanja MC, Hock ET, Loy TS: Passive smoking and lung cancer in nonsmoking women. Am J Public Health 1992, 82:1525-I530.

31. Brownson RC, Alavanja MC, Hock ET: Reliability of passive smoke exposure histories in a case-control study of lung cancer. Int J Epidemiol 1993, 22:804-808.

32. Tobacco Smoke and Involuntary Smoking. World Health Organization; 2004.

33. Proposed Identification of Environmental Tobacco Smoke as a Toxic Air Contaminant. California Environmental Protection Agency; 2005.

34. Adami HO, Lund E, Bergstrom R, Meirik O: Cigarette smoking, alcohol consumption and risk of breast cancer in young women. Br J Cancer 1988, 58:832-837.

35. Band PR, Le ND, Fang R, Deschamps M: Carcinogenic and endocrine disrupting effects of cigarette smoke and risk of breast cancer. Lancet 2002, 360:1044-1049.

36. Fink $A K$, Lash TL: $\mathbf{A}$ null association between smoking during pregnancy and breast cancer using Massachusetts registry data (United States). Cancer Causes Control 2003, 14:497-503.

37. Hunter DJ, Hankinson SE, Hough H, Gertig DM, Garcia-Closas M, Spiegelman D, Manson JE, Colditz GA, Willett WC, Speizer FE, Kelsey $\mathrm{K}$ : A prospective study of NAT2 acetylation genotype, cigarette smoking, and risk of breast cancer. Carcinogenesis 1997, I8:2| $27-2 \mid 32$.

38. Lawlor DA, Ebrahim S, Smith GD: Smoking before the birth of a first child is not associated with increased risk of breast cancer: findings from the British Women's Heart and Health Cohort Study and a meta-analysis. Br J Cancer 2004, 9 I:5 I 2-5I 8.

39. Reynolds P, Hurley S, Goldberg DE, Committee CTSS: Response from authors: Re:Active Smoking, Household Passive Smoking, and Breast Cancer: Evidence From the California Teachers Study. J Natl Cancer Inst 2004, 96:1042- 1043.

40. Reynolds P, Hurley SE, Hoggatt K, Anton-Culver H, Bernstein L, Deapen D, Peel D, Pinder R, Ross RK, West D, Wright W, Ziogas A, Horn-Ross PL: Correlates of active and passive smoking in the California Teachers Study cohort. J Womens Health (Larchmt) 2004, I 3:778-790.

41. Moorman PG, Newman B, Millikan RC, Tse CK, Sandler DP: Participation rates in a case-control study: the impact of age, race, and race of interviewer. Ann Epidemiol 1999, 9:188-195.

42. Slattery ML, Curtin K, Giuliano AR, Sweeney C, Baumgartner R, Edwards S, Wolff RK, Baumgartner KB, Byers T: Active and passive smoking, IL6, ESRI, and breast cancer risk. Breast Cancer Res Treat 2007.

\section{Pre-publication history}

The pre-publication history for this paper can be accessed here:

http://www.biomedcentral.com/1471-2407/8/157/pre pub
Publish with Bio Med Central and every scientist can read your work free of charge

"BioMed Central will be the most significant development for disseminating the results of biomedical research in our lifetime. "

Sir Paul Nurse, Cancer Research UK

Your research papers will be:

- available free of charge to the entire biomedical community

- peer reviewed and published immediately upon acceptance

- cited in PubMed and archived on PubMed Central

- yours - you keep the copyright
BioMedcentral 